ISSN: 0213-2060

DOI: https://doi.org/10.14201/shhme2020381143166

\title{
VÍAS DE COMUNICACIÓN EN LA LEGISLACIÓN VISIGODA ${ }^{1}$
}

\author{
Roads at the Visigoth Legislation
}

\author{
Patricia A. ARGÜELLES ÁLVAREZ \\ Depto. de Prehistoria, Arqueología e Historia Antigua. Facultad de Geografía e Historia. Universidad de \\ Salamanca.C/ Cervantes, s/n.E-37002 SALAMANCA. C.e.: parguelles@usal.es
}

Recibido: 2019-07-24

Revisado: 2019-10-16

Aceptado: 2020-05-04

RESUMEN: El presente artículo analiza la evolución de la legislación visigoda en relación con la normativa del uso y conservación de los caminos. Con el objetivo de conocer las obligaciones y derecho en el tránsito público de las vías en relación con las personas, mercancías y animales, se analizan las fuentes legales romanas, inspiradoras de los códigos tardoantiguos. Así mismo, se completa el trabajo con la visión que ofrecen otras fuentes históricas y arqueológicas para enriquecer la panorámica de conjunto, al justificar la continuidad de la red viaria articuladora del Imperio Romano como base de los ejes visigodos.

Palabras clave: Leyes; Visigodos; Romanos; Espacios públicos; Calzadas.

ABSTRACT: The work hereby analyzes the evolution of Visigoth legislation relating to the set of rules about both the usage and preservation of the roads. With the objective of knowing the stipulation of both the obligations and rights on the public use of the roads, relating to the traffic of people, goods and cattle, the Roman legal sources as inspirers of the Late Antique codes will be studied. So, the work is completed with the scope offered by other historical and archaeological which enrich the panoramical sighting of the ensemble, as justifying the continuity of the articulating road network of the Roman Empire as Visigoth hubs.

Keywordws: Laws; Visigoths; Romans; Public Spaces; Roads.

1 Grupo de Investigación ATAEMHIS. Trabajo realizado en el marco del proyecto: Formación y dinámica de los espacios comunales ganaderos en el Noroeste de la Peninsula Ibérica medieval: paisajes e identidades sociales en perspectiva comparada. HAR2016-76094-C4-4-R.

Abreviaturas: CE: Código de Eurico; CRF: Capitularia Regnum Francorum; CS: Concilio de Sevilla; CT: Código de Teodosio; CV: Constitución de Valentiniano; DJ: Digesto de Justiniano; ER: Edicto Rotario; IS: Isidoro de Sevilla; LB: Lex romana Burgundiorum; LG: Ley Gungobarda; LP: Ley Pippini; LV: Lex Visigothorum; VSF: Vida de San Fructuoso. 
SUMARIO: 0 Introducción. 1 Las leyes. 1.1 Sobre reparaciones y construcciones viarias. 1.2 Sobre límites viarios. 1.3 Sobre viajeros. 1.4 Sobre mercancías y animales. 2 Continuidad en la infraestructura romana. 3 Conclusiones. 4 Fuentes históricas. 5 Referencias bibliográficas.

\section{INTRODUCCIÓN}

Debemos comenzar este estudio de legislación visigoda adentrándonos en el análisis del tratamiento de la regulación viaria en las fuentes romanas. Ello es debido a que la legislación visigoda tomará como base inspiradora el conjunto de textos jurídicos romanos, medidas que continuarán siendo aplicadas mediante el Codex Theodosianus, y más tarde el Breviario de Alarico en una aplicación territorial de comunidades romano-bárbaras. Existen, por tanto, ejemplos nomotéticos de inspiración romana ${ }^{2}$ que se reproducirán en códigos no solo visigodos sino también francos o germanos.

El profundo desarrollo tanto por amplitud como por calidad técnica de la normativa a estudiar ha hecho que el conjunto de corpora visigodos sea un referente en la historia del derecho nacional. La dualidad romana y germánica de la población visigoda hizo que también en el ámbito jurídico existiera una legislación dual de los códigos hispanorromanos, ampliando el contenido de las nuevas necesidades creadas por el nacimiento del reino de Espańa en el occidente europeo.

Los ejemplos analizados que a continuación presentamos han sido examinados desde una perspectiva global para conocer la regulación romana de las últimas centurias imperiales y, así, poder explicar cuál ha sido la herencia en el pensamiento de los legisladores visigodos. Así mismo, rematamos este estudio con una perspectiva multidisciplinar que ofrece datos relacionados no solo con la regulación oficial sino también con otros testimonios literarios, restos epigráficos y arqueológicos.

\section{LAS LEYES}

El análisis legislativo presentado en las siguientes páginas se ha estructurado en cuatro apartados: en el primero se detallará la información recabada correspondiente a reparaciones y regulaciones de infraestructura. En el segundo el análisis se va a enfocar en aclarar qué pasos eran considerados caminos y cuáles de ellos eran públicos y cómo se regulaban sus límites viarios. Para el bloque tres nuestra atención se centrará en poder compilar la información que tenemos sobre viajeros visigodos y cómo estos describen los caminos y, de este modo, cerraremos el bloque cuatro asociándolo al paso viario, pero en ese caso de mercancías y animales.

2 Para mayor detalle sobre una compilación de normativa viaria romana, consultar la obra de VAN Tilburg, Cornelis. Traffic and congestion in the Roman Empire. London: Routledge, 2007, pp. 29, 34, $128-136$. 
Además, existe un quinto apartado que, dejando a un lado el propio estudio legislativo e histórico, completa el panorama de las comunicaciones visigodas hispanas desde un punto de vista arqueológico.

\subsection{Sobre reparaciones y construcciones viarias}

El Breviario de Alarico, también concocido como Lex Romana Visighotorum, fue promulgado en el 506 para dar normativa a los jueces romanos en casos ante el tribunal. Este texto recoge una selección de leyes del denominado Codex Theodosianus, más otras de producción original ${ }^{3}$. Es una obra postclásica de derecho romano privado, una vez que desaparece el Imperio Romano. Sin duda, claro ejemplo de cómo continúa en uso la legislación romana sin sufrir apenas ninguna modificación. Nos interesa especialmente el libro XV en relación con De operibus publicis y De aquaeductu, recuperado del ya citado Codex Theodosianus del año 438, en donde se atesora la normativa en relación con la reconstrucción de obras de ingeniería tales como edificios, termas, murallas o acueductos ${ }^{4}$. El Código de Teodosio en relación con La construcción y reparación de caminos acopia los edictos de seis emperadores desde el año 319 hasta el 423. Sabemos que para el 399 las calzadas estaban en tal pésimo estado de conservación que se hace una llamada obligada para la colaboración de cualquier hombre del Imperio 5 . Parece ser que estas ideas se inspiraron en varios edictos de época imperial depositadas también en la Digesto ${ }^{6}$.

El recopilatorio legislativo de la Digesto de Justiniano fue decretado en el año 533. De él nos interesan los "Comentarios de Pomponio a Sabino, libro XXX" (siglo II) y de Ulpiano en "Comentarios al Edicto, libro LXVIII" (siglo III) sobre la normativa viaria. Pomponio, al Edicto De los lugares y caminos públicos ${ }^{7}$, reitera la idea de que lo público es de pertenencia grupal y para uso de todos. Además, los caminos vecinales, al igual que los militares, son de condición pública.

Ulpiano por su parte, en el título De los lugares y caminos públicos y que no se haga cosa alguna en lugar o camino público ${ }^{8}$, dilucida que nadie tiene permitido levantar monumentos (aunque fueran para la comunidad) en vías públicas (incluyendo también fosos o cloacas... $)^{9}$. Con relación a esto, queda clara la intención de que las obras realizadas en

3 Codici Theodosiani. Legis Romanae Wisigothorum. Fragmenta ex codice palimpsesto Sanctae Legionensis Ecclesiae. Matriti: apud Ricardum Fe, Regiae Academiae Typographum, 1896.

4 CT. XV, I. II. Edición consultada para esta y sucesivas referencias: Codex Theodosianus (ed. Theodor Mommsen y Paul M. Meyer). 2 vols. Berlin: Weidmann, 1905.

5 CT. III. Introduce por tanto la idea de que el uso comunitario de los caminos supone, así mismo, una obligación grupal en su conservación.

6 En el año 396, los emperadores Arcadio y Honorio emanan una constitución que posteriormente queda recogida en la Digesto de Justiniano; en Malavé Osuna, Belén. Régimen jurídico financiero de las obras públicas en el derecho romano: los modelos privado y público de financiación. Madrid: Dykinson, 2007, p. 144.

7 DJ. VII. Edición consultada para esta y sucesivas referencias: Cuerpo del derecho civil romano. $T$. III. Digesto (traducción y compilación de Ildefonso L. García del Corral). Barcelona: [Jaime Molinas, editor], 1897.

DJ. VIII.

9 DJ. VIII, 26, 27, 28. 
espacios públicos, aunque para beneficio comunitario, nunca pueden perjudicar a un particular ${ }^{10}$, y, en caso contrario, el pretor se opondría con un interdicto. Por consiguiente, parece que se acentúa el pensamiento de que cosa alguna no puede ser puesta en una vía pública: vedo que en vía publica o en camino publico se haga o se introduzca algo por lo cual se deteriore esta vía o este camino. Esto incluiría también cualquier posible deterioro en el suelo que pudiera ser provocado por el paso de un animal ${ }^{11}$. Al igual que en el texto de Pomponio, se especifica que la vía pública es aquella que los griegos llamaban «reales» y que para los romanos eran las pretorianas y consulares, mientras que las privadas serían las agrarias, coincidiendo en que las vecinales son públicas si conducen a pueblos y se financiaron con fondos comunes. Ideas repetidas en Papiano: «Del cargo de los ediles» sobre De la vía pública y de si dijera que en ella se hizo cosa alguna, ampliando en este epígrafe la idea de dejar la vía libre de posibles desagües de casas vecinas, así como que las paredes de construcciones colindantes a la vía estén limpias y en buen estado ${ }^{12}$.

Este tema ya había sido adelantado en la constitución de las Novelas de Valentiniano III del año $411^{13}$, en donde se presta especial atención al caso de la «reparación de rutas» ${ }^{14}$. Se señalan expresamente trabajos de conservación y arreglo en los caminos militares ${ }^{15} \mathrm{y}$, posiblemente, otras construcciones análogas también militares, tales como fortificaciones, elementos de transportes, etc., eliminando exenciones contributivas vigentes hasta la fecha para estos propósitos ${ }^{16}$.

Se mantiene, por tanto, la idea ya formulada por Roma sobre financiación pública de obras comunales ${ }^{17}$ en la ley promulgada por el Rey Pipino (siglo viri) del código del pueblo lombardo. La Lex Pippini es el único texto legal con cronologías altomedievales que explícitamente recoge la importancia de preservar tradición y costumbres de los antecesores, recordando que las vías y puentes dentro del reino habrían de ser reparadas por los entes locales en donde se emplazasen, tal y como se habría hecho desde siempre, pues los caminos eran de uso de todos, incluyendo zonas de paso en los ríos, aunque no existieran construcciones como tal ${ }^{18}$. Así mismo, se insta a que para acometer estos

10 Se entiende por «lugar público» los campos, vías públicas, zonas con casas y solares.

11 DJ. VIII, 20.

12 DJ. X, 1; CT. XV, I. I.

13 CT. I, 4, 3. Ideas mantenidas en el Código de Eurico. Véase p. 148.

14 Apartado 10. 3 del texto de las Novelas de Valentiniano dentro del Código Teodosiano, I. Sobre la financiación de las reparaciones viarias en el Imperio Romano. Véase Melchor Gil, Enrique. "Sistemas de financiación y medios de construcción de la red viaria hispana». Habis, 1992, vol. 23, pp. 121-137.

15 En el caso del mundo visigodo no existen normativas que diferencien la regulación del paso en vías púbicas o militares, al contrario que en el mundo romano donde extraemos la idea de que no todos los caminos militares eran accesibles a la población. Si un viajero tenía necesidad de salir de una vía pública hacia la militar, para la cual no tenía permiso, debería hacerlo viajando en animales de carga públicos: VAN TiLbURG, Traffic and congestion in the Roman Empire, p. 45; Título V: Postas públicas, correos y correos extraordinarios, del Código de Teodosio recoge toda una normativa sobre el uso de estos establecimientos, paquetería y el uso de animales de transporte (CT.V.3).

16 Malavé Osuna, Régimen jurídico financiero de las obras públicas en el derecho romano, pp. 142-143.

17 Nos referimos a los ya citados comentarios de Pomponio y Ulpiano. Véase p. 145.

18 LP. 19. 20. Edición consultada para esta y sucesivas referencias: Lex Pippini recogida en «Leges Langobardorum». En Monumenta Germaniae Historica. Legum Tomus IIII. Hannoverae: Expensis Bibliopolii Aulici Hahniani, 1868. 
arreglos (incluyendo la reparación de iglesias) sería necesario buscar financiación mediante recaudación al pueblo ${ }^{19}$.

\subsection{Sobre limites viarios}

En el 654 el rey Recesvinto promulga el Liber Iudiciorum, conocido también como la Lex Visigothorum. La obra es una compilación de diversas referencias sobre accesos, comunicaciones y $\operatorname{pasos}^{20}$. Se puede deducir a rasgos generales que prevalece la normativa vigente romana y simplemente se adapta a la sociedad visigoda. Así mismo, como ya adelantábamos al inicio de este estudio, las calzadas diseñadas por los romanos siguen estando en uso tanto para el tráfico comercial como para el de viajeros, siendo escasas las referencias sobre su mantenimiento en los siglos v-VII, si bien, incluso, algún acceso secundario podría haber quedado abandonado ${ }^{21}$.

En el capítulo referente a "De los hitos y de los mojones», la ley revela que aquellos hitos y mojones existentes de "antiguo" (antiquis terminos et limites) se mantendrían tal y como fueron establecidos pretéritamente y no serían "arrancados» por ninguna reforma de particulares (commotione). Es decir, observamos nuevamente la intención de transmitir la idea de que es importante conservar lo heredado. Así mismo, se señala que en el caso de que alguien arrancase algún «fixo» o lo rompiese para poder invadir tierra ajena, de ser un hombre libre debería indemnizar al perjudicado veinte sueldos por cada mojón, y si fuera siervo recibiría 50 azotes por cada señal deteriorada. En el caso de haber cometido el error de arrancar el mojón sin maldad, por arar o plantar, debería restituirse en presencia de los vecinos y no sería castigado ${ }^{23}$.

Los problemas por las señalizaciones de caminos y límites territoriales están muy presentes en todos los textos visigodos y así se corrobora con el II Concilio de Sevilla del año 619, para la querella de los obispos Fulgencio y Honorio. En este caso, el problema vino dado por la pertenencia de ciertas iglesias al territorio Celtiense o Reginense. Entonces se propuso proceder con el estudio de antiguos límites, que conservaban «viejas señales» (mojones), para dar respuesta a la pertenencia territorial de la basílica cuestión de debate ${ }^{24}$.

Retomando el contenido de la Lex Visigothorum sobre cómo delimitar el territorio, se contempla la mediación para disputas por lindes que habían sido «antiguamente» ya delimitadas, ya fuera mediante pilas de tierra (aggeres), con los citados mojones a modo de términos de posesiones (fundorum), o «lápidas» clavadas como marcas territoriales.

19 LP, 4. 5.

20 LV. X, 3, 1. Edición consultada para esta y sucesivas referencias. Liber Iudiciorum (estudio preliminar de Rafael Ramis Barceló; traducción y notas de Pedro Ramis Serra y Rafael Ramis Barceló). Madrid: Agencia Estatal Boletín Oficial del Estado, 2015.

21 Carr, Karen Eva. Vandals to Visigoths: Rural Settlement Patterns in Early Medieval Spain. Ann Arbor: University of Michigan Press, 2002, p. 147.

22 Es decir, existentes desde tiempo romano.

23 LV. X, 3, 2.

24 Vives Gatell, José. Concilios visigóticos e hispano-romanos. Vol. 1. Barcelona-Madrid: Consejo Superior de Investigaciones Científicas, 1963, p. 164. 
Si estas faltasen y hubiera disputas, se buscarían posibles señales grabadas en los árboles (decurias), intentando demostrar que dichas marcas fueron grabadas en tiempos primitivos $^{25}$.

Otra referencia a la gestión de las tierras, y cómo las lindes de época romana habrían de prevalecer sobre otras posteriores, se deduce del procedimiento de transferencia de tierras por venta, donación o algún tipo de transacción en donde se mantendría vigente la autoridad romana para estas cronologías tardoantiguas ${ }^{26}$; pero, si no hubiese mojones o señales evidentes (signis aut limitibus), se acudiría a un juez ayudándose de las gentes longevas y más informadas para que no existiera fraude. En el caso de demostrarse tal, se consideraría un castigo por invasión (damnum pervasionis) (si hubiera sido un siervo y lo ocultase a su amo, el castigo era de 200 azotes en público sin perjudicar al amo por ello) $)^{27}$.

Dejando a un lado los hitos y límites de tierras, en lo concerniente a las propias vías públicas y cómo delimitar estas, la ley refleja cómo los caminos que transcurrían hacia ciudades no podían ser obstruidos y debían conservar un margen lateral de 60 pies a cada lado ${ }^{28}$, para poder hacer una parada, si el viajero lo deseaba, sin importunar al resto de viandantes ${ }^{29}$. En caso de que la ley no fuera cumplida, se contemplaban diversos gravámenes en función de la posición social del infractor. Por otro lado, donde existieran pastos, viñas y cultivos cerca del camino habría que poner cercas o hacer fosos divisorios respecto del camino público ${ }^{30}$. La misma idea ya fue previamente recogida en el Código de Eurico, hacia finales del siglo v, en relación con la pena de 12 solidi a hombres libres y 100 azotes a siervos que inhabilitaran parte de un camino público ${ }^{31}$.

Sobre los preceptos del Código de Eurico y anterior a la Lex Visigothorum, la Lex Gungobarda o Código Burgundio, atribuido a Gundebaldo (principios del siglo vi), reitera literalmente la sanción de 12 solidi por cerrar caminos públicos y puntualiza sobre la libertad del viajero para destrozar los nuevos límites ilegales ya sean de cercos o nuevos cultivos $^{32}$. Además, si un hombre libre destrozase un límite legal de una finca y permitiese

25 LV. X, 3, 3.

26 Sobre las disputas por límites, lindes, uso de tierras, vallados, vías, etc., Higino, en «De generibvs controversiarvm», resume los pleitos más comunes en el mundo romano, pp. 47-63. Referencia empleada para esta y sucesivas citas: Hyginvs et Sicvlvs Flaccvs. Opvscula Agrimensorvm Vetervm (traducción y comentarios de M. ${ }^{a}$ J. Castillo Pascual). Logrońo: Universidad de La Rioja, 2011.

27 LV. X, 3, 5. Véase también, Thompson, Edward Arthur. Los godos en España. Madrid: Alianza Editorial, 1969, p. 157.

28 Según San Isidoro es un acto cuadrado.

29 En «De limitibus», dentro del Opvscula Agrimensorvm Vetervm de Higino, se aludió a la obligatoriedad de que se respetasen ciertas medidas en las vías, no solo en ancho y márgenes sino también en cuanto a las distancias y entre mojones; en Hyginvs et Sicvlvs Flaccvs, Opvscula Agrimensorvm Vetervm, pp. 5-6, 31.

30 LV. VIII, 4, 25.

31 Con Leovigildo queda marcada la distinción entre maiores personae e inferiores, pues será siempre el amo el encargado de reparar el camino (CE. XXII, 172). Edición consultada para esta y sucesivas referencias: Código de Eurico (edición, palingenesia, índices por Álvaro d'Ors). 2. a ed. Madrid: Boletín Oficial del Estado, 2014.

32 Véase nota n. ${ }^{\circ} 51$. 
el paso animal, pagaría un sueldo por cada animal invasor del territorio privado. También, si se rompiera una cerca solo por el simple hecho de causar molestia, se ingresaría un tremissis por cada estaca dañada (en el caso de haber sido un esclavo, 100 azotes y la reparación personal del cierre) $)^{33}$.

Tema recurrente el de los límites viarios al que también se le dedica un epígrafe en la ley romana Burgundiorum de inicios del siglo vi, aplicada solo a los ciudadanos romanos presentes en el reino de los borgoñones. En el título XVII: De clausis itineribus vel aliis servitutibus (sobre los caminos cerrados y otras servidumbres), se establece que no se puede ocupar, ni cerrar, ni labrar el camino público que comunalmente se ha dejado entre los campos. Si esto ocurriere, se ha de forzar al autor del hecho a la reparación del suelo, haciendo mención no solo al suelo del propio camino sino también en el caso de puentes ${ }^{34}$. Así mismo, se establece el deber de respetar la vía pública vecinal ${ }^{35}$.

Parece considerarse de servidumbre los caminos cerrados; ello muestra que la legislación burgundia no se asentó sobre el derecho romano clásico sino sobre el derecho romano del Bajo Imperio inspirado en códigos como el de Teodosio o la Sententia Pauli ${ }^{36}$.

\subsection{Sobre viajeros}

En tiempos visigodos la seguridad del viajero no estuvo siempre garantizada ${ }^{37}$. El obispo Braulio de Zaragoza avisaba del peligro de viajar por tierra en una carta escrita al también obispo Valentinus en el año $625^{38}$. Así pues, denunciaba que las gentes de la región del Ebro no querían viajar a Valencia por temor a toparse con los ladrones de caminos. Parece que, pese al gran esfuerzo de los monarcas visigodos en dictar leyes que penaban la delincuencia, estos no fueron capaces de aplacar la inseguridad de los viajeros ${ }^{39}$. Se conocen textos sobre viajes por Hispania de obispos que, aun acompañados de un

33 LG. XXVII, 1, 3, 4. Edición consultada en todas las referencias del trabajo: Drew, Katherine Fischer. The Burgundian Code. Book of Constitutions or Law of Gundobad. Philadelphia: University of Pennsylvania Press, 1972.

${ }_{34}$ Hoc etiam et de pontium reparatione servandum (LB. 17. 1). Edición de referencia en esta y sucesivas citas: «Lex Romana Burgundionum» (ed. R. L. von Salis). En Monumenta Germaniae Historica. Legum Sectio I. Tomi II. Pars I. Hannoverae: Impensis Bibliopolii Hahniani, 1892.

35 LB. 17. 1. Se aclara que no solo las vías principales eran de uso público, sino que también las vecinales, aunque usadas por una minoría, se consideraban un bien de la comunidad.

${ }_{36}$ Sententia Pauli: 1. 14 De via publica. 1. 15 De quadruples damnum intulerit. Sobre textos romanos en los que se inspira el título XVII de la Lex Romana Burgundionum, véase Ortuño Pérez, M. ${ }^{a}$ Eugenia. "Algunas consideraciones sobre las servidumbres en la Lex Romana Burgundionum». Anuario da Facultade de Dereito da Universidade da Coruña, 2008, vol. 12, pp. 707-721 (Ref. 17-20).

37 Orlandis Rovira, José. Historia del reino visigodo español: los acontecimientos, las instituciones, la sociedad, los protagonistas. Madrid: Ed. Rialp, 1988, pp. 42-43.

38 Ep. 24: quoniam regiones nostrae homines pergere illuc pavent ob latrones, en BraUlio CAESARAUgustanus, Isidorus Hispalensis. Epistulae, Confessio uel professio Iudaeorum ciuitatis Toletanae (eds. Ruth Miguel Franco y José Carlos Martín-Iglesias). Turnhout: Brepols, 2018.

39 LV. VI, 4, 2 y VII, 3, 5; CE. VII, 104. 
gran séquito armado, tenían miedo de cabalgar por caminos rurales ${ }^{40}$. El desplazamiento empeoraba aún más al saber que la mayoría de las vías y puentes romanos, ya entrado el siglo v, seguían siendo transitados, pero sus firmes eran pésimos, pues parece que no se habían acondicionado desde época romana ${ }^{41}$. Todo ello hace que en estas centurias empiece a cobrar protagonismo el viaje por pasos fluviales en detrimento de los pasos terrestres. No obstante, dicha solución no sirvió para evitar a los forajidos y poder realizar viajes más confortables, ya que los bandidos pronto abordaron también las orillas, como fue el caso del Guadalquivir ${ }^{42}$.

Otro ejemplo de la presencia de ladrones y bandidos deambulando por los caminos se menciona para el caso de la vía Augusta en los textos del siglo xvi de Al-Maqqari basados en fuentes de los siglos $\mathrm{X}-\mathrm{XII}^{43}$. Parece ser que las postas (las antiguas mansiones documentadas en los Vasos de Vicarello) de los caminos (al menos en la vía Augusta), al estar lejos de las ciudades, servían como sitios de cobijo a ladrones y vagabundos, siendo el viajero un blanco fácil. Así mismo, el deterioro de las vías y sus mojones llevó a la desaparición de gran parte de esta infraestructura por falta de conservación ${ }^{44}$.

Otra referencia sobre salteadores de caminos se narra en la vida de Valerio del Bierzo, cuando indica que era algo común en la zona de Castro Pedroso ${ }^{45}$. Parece, pues, que la principal preocupación del viajero sería el cómo salir ileso de un posible enfrentamiento con un salteador de caminos, pero sabemos que también podía existir otro tipo de inseguridades. La Lex Visigothorum recoge el caso de tropezar con fosos-trampa preparados para la caza. El cazador debía avisar a los vecinos más cercanos y procurar que fueran zonas lejanas a caminos. Informados los lugareńos, a estos no se les indemnizaría en caso de accidente, pero sí a su ganado. Por supuesto, a los ladrones que cayesen en estas trampas tampoco se les indemnizaría de modo alguno. A los forasteros sin conocimiento de dichos fosos se les pagaría un tercio de lo establecido por la ley en caso de incapacidad

40 En relación con la movilidad de clérigos por los caminos aludimos a la referencia de los religiosos expulsados de sus órdenes (recogido en los concilios visigodos: IV C. Toledo 52.53.55; VI C. Toledo 6; VII C. Toledo 5 y XIII C. Toledo 2) que, fuera de la supervisión eclesiástica, pasaban a ser vagabundos o fugitivos y se veían obligados a vagar como nómadas por los caminos; en Andrés SAnz, M. a Adelaida; Codoñer, Carmen; Iranzo Abellán, Salvador; Martín, José Carlos y Paniagua, David. La Hispania visigótica y mozárabe: dos épocas en su literatura. Salamanca: Universidad de Extremadura-Ediciones Universidad de Salamanca, 2010, p. 171.

41 Recordamos que el Código Teodosiano recoge el deplorable estado de las comunicaciones terrestres hacia el año 399 (CT. III).

42 CARr, Vandals to Visigoths, pp. 159-162.

43 A mediados del siglo v esta vía no había sido reacondicionada y su estado de deterioro era considerable; en Collins, Roger. Early medieval Spain. Unity in Diversity, 400-1000. London: Palgrave Macmillan, 1995, p. 4 y CARr, Vandals to Visigoths, p. 146.

44 Gozalbes Cravioto, Enrique. «La vía romana de Cástulo a Cádiz en textos medievales y del siglo XVI». En Caminería hispánica. Actas del IV Congreso Internacional, celebrado en Guadalajara (España), julio 1998. Madrid: Ministerio de Fomento, 2000, vol. I, pp. 73-90 y Martín Castro, Antonio. "Ad Aras y La Carlota. Estado actual de una hipótesis a la luz de nueva información». Antiqvitas, 2010, vol. 22, pp. $107-119$ (p. 109).

45 "Valerio del Bierzo. Ordo Querimonie prefati discriminis», 1.7.24. En DíAz y DíAz, Manuel Cecilio. Valerio del Bierzo. Su persona. Su obra. León: Centro de Estudios e Investigación San Isidoro, 2006, pp. $248,254,275$. 
o muerte, entendiendo que las trampas no estaban lo suficientemente lejos del paso viario $^{46}$.

El mundo visigodo reguló la libre navegación por los ríos, por lo que la legislación hubo de registrar las normas para los viajeros marítimos ${ }^{47}$. Por ejemplo, se prohibía a los propietarios de las tierras ribereńas colocar obstáculos en los cursos fluviales, impidiendo o dificultando su navegabilidad contra el provecho común, negando la posibilidad de especular a favor de intereses particulares ${ }^{48}$. Dado el caso, el castigo era el pago de cinco sueldos (hombres libres) y cincuenta azotes (siervos), o el doble en el caso de poner impedimentos en ambas orillas del río. Lo mismo sucedía, como ya hemos referido anteriormente, si se ponía "vallum» para cerrar un camino público, en este caso en un paso ribereño ${ }^{49}$.

En la Vita Fructuosi se recoge el viaje de Fructuoso desde Sevilla a Cádiz, por río. Sabemos que tardó tres días en una distancia de menos de 150 kilómetros; aun así, parece que era más seguro el viaje por río que por tierra ${ }^{50}$.

En relación con cierres y obstáculos en zonas públicas se contemplaba la posibilidad de que el propietario cultivase demasiado cerca del río o la calzada sin poner una cerca, automáticamente eximiría de responsabilidad sobre posibles daños ocasionados al viandante ${ }^{51}$. Igualmente, las zonas de pastizales sin vallas se consideraban "públicas», aunque con una limitación temporal, pues el viajero tendría derecho a dejar sus pertenencias y dar pasto a sus animales por un máximo de dos días (a excepción de tener permiso del dueño de la tierra para quedar más tiempo), quedando prohibido arrancar árboles de raíz, y solo talar árboles pequeńos para forraje ${ }^{52}$. Pensamiento reiterado en la ley euridiciana sobre el derecho del viajero a vivaquear en tierra ajena y a hacer fuego ${ }^{53}$. Recordando, tal y como ya hemos referido, que en el caso de que el viajero sufriera algún daño con cepos o fosos el propietario del terreno se haría responsable $e^{54}$.

En este caso, la normativa legal visigoda sí difiere de la romana, pues encontramos en Antonino Pio, y posteriormente en Instituciones de Gayo ${ }^{55}$, el derecho del propietario

46 LV. VIII, 3, 9.

47 LV. VIII, 4, 29. El Código Teodosiano (CT. XIII) recoge la legislación romana marítima y fluvial. Véase Cañızar Palacios, José Luis. «Los Navicularii Hispaniarum en el contexto de la documentación legislativa tardo antigua». Hispania Antiqva, 2009-2010, vol. XXXIII-XXXIV, pp. 295-310. Véase también Orlandis Rovira, Historia del reino visigodo español, p. 197.

48 Sobre otras regulaciones de obstáculos en pasos fluviales, véase nota n. ${ }^{\circ} 68$.

49 LV. VIII, 4, 24.

50 En Díaz y Díaz, Manuel Cecilio. La vida de San Fructuoso de Braga. Estudio y edición crítica. Braga: Diário do Minho, 1974, n. ${ }^{\circ} 14$.

$51 \quad$ LV. VIII, 4, 25, 28.

52 LV. VIII, 4, 27. También recoge la ley euridiciana, siguiendo la normativa de Leovigildo, la pena regulada hacia el propietario de la finca en el caso de robar el ganado del viajero (CE. XXII, 170).

53 CE. XVIII, 170. Aportación novedosa de la legislación germánica que no se recoge en el caso romano.

54 LV. VIII, 3, 9.

55 Gayo. Institvtionvm. Leipzig: Ed. E. Seckel, B. Keubler, 1935 (2.1-14). 
del predio a prohibir la entrada de persona ajena a su fundo ${ }^{56}$. Aunque, por otro lado, se mantiene en el mundo visigodo la libertad de caza instaurada por Roma tal y como en la Lex Romana Visigothorum o la Lex Romana Burgundionum.

En paralelo a la legislación visigoda, la Ley Langobarda en el Edicto de Rotario, vigente desde el 643 para la población itálica de origen lombardo, hace referencia a la «vía pública» en un ámbito no contemplado en ninguna ley previa. En este caso se tiene en cuenta que, si en una vivienda cercana se produjera un fuego y este se extiende al camino, si solo hubiera daños leves y el fuego remite, no se buscarían responsabilidades, entendiendo que no se quería hacer deterioro en un bien común ${ }^{57}$. En contrapartida, la Lex Visigothorum, aplicable en territorio hispano desde el 654, contempla el caso del fuego realizado por el viajero en una tierra donde descansaba (y no por los locales como es el caso del Edicto Rotario), pensando en la posibilidad de que, si dicho fuego se extendiera, sería el transeúnte el responsable de los perjuicios causados ${ }^{58}$.

Otra alusión hacia los viajeros se trata en el texto autobiográfico de Valerio del Bierzo, quien menciona su retirada al monasterio de Santa Rufiana ${ }^{59}$ (enclavado muy próximo al Camino de Santiago y del cual sabemos que corresponde al monasterio de Compludo $^{60}$ ) fundado por San Fructuoso de Braga ${ }^{61}$. En sus reflexiones, cita la iglesia de San Félix cerca de la cual había un camino de montaña desde el pueblo más cercano: sub illo monte publica discurreret strata cum autem in ea ingressi fuissent, obviaverunt multitudinem hominum multa bovum juga ducentium ${ }^{62}$. Sabemos que Valerio viajó desde el monasterio hasta Toledo en varias ocasiones, por lo que la red de comunicaciones de la

56 García Garrido, Manuel. «Derecho a la caza y "Ius Prohibendi” en Roma». Anuario de Historia del Derecho Español, 1959, vol. 26, pp. 269-336.

$57 \quad$ ER. 148.

58 LV. VIII, 2, 3. En la cita 56 se menciona el derecho del viajero a realizar un fuego al vivaquear (según el Código de Eurico); además, en este caso, el del viajero se consideraría incendio involuntario si causase algún daño.

59 Actualmente San Pedro de Montes (diócesis de Astorga); en DíAz y DíAz, La vida de San Fructuoso de Braga, p. 89, ref. 1.

60 El rey Chindasvinto y su esposa Reciberga concedieron grandes posesiones al monasterio de Compludo, en el año 616, con motivo del VII Concilio de Toledo, "para el sustento de tantos anacoretas y eremitas y de cuantos en aquellos parajes practiquen la vida monástica», constituyendo la primera donación real de la historia espańola (El tumbo negro de la Catedral de Astorga, fols. 11v, 15r, 82, n. ${ }^{\circ} 279$ ).

61 Díaz y Díaz, La vida de San Fructuoso de Braga, p. 85; VSF. 3.

62 La iglesia de San Félix está ubicada en Vilar de los Barrios (Ponferrada) en el cruce de dos caminos, el Maragato y el de San Esteban; en Frighetro, Renan. Valério do Bierzo. Autobiografía. Noia (A Coruña): Ed. Toxosoutos, 2005, p. 76, cita 246. El término «strata» haría alusión a un camino estrecho de pocas dimensiones (relacionado con los pastores), "pues sería más correcto el uso de "via” para caminos de mayores dimensiones y espacio para tráfico rodado», según se explica en Isidoro de Sevilla. Etimologías (ed. José Oroz Reta y Manuel A. Marcos Casquero). Madrid: Editorial Católica, 1982, 16.4, 16.6). Sobre la «strata publica» citada por Valerio del Bierzo, Sículo Flaco detalla cómo han de ser los mojones, el tipo de taludes que han de dividir los caminos de las fincas y especifica en relación con la tipología de vías (vecinales, comunales, privadas) así como sus características; en Hyginvs et Sicvlvs Flaccvs. Opvscula Agrimensorvm Vetervm, pp. 90-92. Sobre la terminología toponímica véase Álvarez Maurín, María Pilar. Diplomática asturleonesa. Terminología toponímica. León: Universidad de León, 1994, pp. 338-339. 
antigua Roma de Asturica Augusta debía seguir en pleno funcionamiento ${ }^{63}$. También se retiró al cercano Castro Pedroso, donde ya hemos hecho referencia a las habituales apariciones de salteadores de caminos ${ }^{64}$.

\subsection{Sobre mercancias y animales}

La red viaria era compartida entre viajeros, animales y transporte de mercancías ${ }^{65}$. Para el mundo romano existe numerosa información acerca de las postas, permisos de viaje, uso de carros y animales, o sobre el comercio y los transportes ${ }^{66}$. No obstante, la normativa visigoda no es muy extensa en cuanto a los decretos sobre el comercio de la época ${ }^{67}$. El Código de Eurico, en su capítulo XIII, De transmarinis negotiatoribus, compila una extensa normativa que, sin duda, está inspirada en códigos romanos, como el de Teodosio, y que, posteriormente, también se mantiene en la Lex Visighotorum. No obstante, ni la Lex Visigothorum ni el Código de Eurico hacen referencia alguna sobre normas de transporte de mercancías terrestre ${ }^{68}$. Llama la atención que la propia fuente base de inspiración, el Código teodosiano, sí que distingue entre el comercio terrestre y el marítimo. Sobre el terrestre, se alude, por ejemplo, a un tope de 1.000 sacas de monedas que podrían acarrear los animales en los transportes ${ }^{69}$, e innova con un riguroso cumplimiento legal en relación al cursus publicus: Postas públicas, correos y correos extraordinarios, es decir, dónde se debían emplazar postas, cuáles eran los derechos de viaje y cómo funcionaban los correos (CT, V). Parece ser que el mal estado de los caminos, la necesidad de rehabilitación de puentes y las limitaciones animales al llevar pesadas cargas, favorecían

63 Asimismo se alude a que el séquito real de Leovigildo viajó por una viae publica a la civitas de Toledo; véase EsDERs, Stefan. «Reisende soll man nicht aufhalten? Über Infrastrukturen sowie erwünschte und unerwünschte Mobilität im westgotischen Spanien». En CzEguHN, Ignacio et ál. (coords.). Wasser-WegeWissen auf der iberischen Halbinsel vom Römischen Imperium bis zur muselmanischen Herrschaft I. Tagungsband zur gleichnamigen Tagung in Elche 2014. Baden-Baden: Nomos Verlag, 2016, pp. 151-182 (p. 157).

${ }^{6}$ "Valerio del Bierzo. Ordo Qverimonie prefati discriminis», 1.7.24. En DíAz y Díaz, Valerio del Bierzo, pp. 248, 257, 275; y Andrés Sanz, Codoñer, Iranzo Abellán, Martín y Paniagua, La Hispania visigótica y mozárabe, p. 206. Sobre asaltadores véase nota n. ${ }^{\circ} 45$.

65 CARr, Vandals to Visigoths, p. 147.

66 Van Tilburg, Traffic and congestion in the Roman Empire, pp. 45-62.

67 Orlandis Rovira, Historia del reino visigodo español, p. 188.

68 De los mercaderes transmarinos (LV. XI, 3): alude al comercio transmarino y contempla casos como la venta de productos robados, contratación de mercenarios e incluso la excepción de pleitos con leyes propias de ultramar; en D’Ors, Álvaro. «Los “transmarini negotiatores” en la legislación visigótica». En Estudios de Derecho Internacional. Homenaje al profesor Camilo Barcia Trelles. Santiago de Compostela: Universidad de Santiago de Compostela, 1958, p. 469.

69 CT. IX. 22-23. Sobre el transporte de dinero y metales Gregorio de Tours, en el año 584-585, menciona el momento en el que Gundovaldo deja a los enemigos al borde del Garona con caballos y dromedarios llenos de oro y plata. Gregorio de Tours. Historia Francorum (traducción E. Brehaut), 1916 (VII. 25). 
el comercio marítimo, quedando el terrestre solo para cortas distancias o transportes ligeros, pero rentables, es decir, productos de lujo ${ }^{70}$.

Se conocen pasos trashumantes en la Hispania republicana y su continuidad en centurias visigodas está igualmente documentada ${ }^{71}$. La trashumancia visigoda era común en regiones apartadas cuyo eje principal se basaba en el uso de la "vía de la Plata»" ${ }^{72}$. Además, en el caso de esta calzada podríamos aventurar el acondicionamiento y continuidad de uso en estructuras viarias, como sería el ejemplo de la villa de Los Villares (Salamanca) con fases de ocupación de los siglos $\mathrm{V}-\mathrm{VI}^{73}$.

Parte de dicha teoría se completa con unas pizarras transcritas por M. Gómez Moreno $^{74}$, en donde se lee la palabra stratus, es decir, derecho de tránsito por la vía pública, y pedagium, por lo tanto existía peaje; si bien es cierto que no todos los investigadores coindicen en la lectura de [st]ratus y la interpretación de pedag[ium? $]^{75}$. Se deduce, por tanto, que en ese paraje era necesario el pago de un peaje para el tránsito. Parece que tras los renglones con números y la separación con una raya horizontal hay una "execratio»: [[st]]ratus feci; turbat / qui lesserit pedag[ium?] / in soca boina. Á. Canellas López ${ }^{76}$ aclara que este texto es como una execración contra quien moleste a otro en el tránsito del coto del matorral, quizá alude al término "in soca boina», posiblemente interpretado como «en el lugar bobino» «en el coto de un bosque», son varias y no definitorias las posibles interpretaciones. En definitiva, un posible peaje ${ }^{77}$ de ganado en terrenos acotados, o pagos de campesinos que utilizarán el usufructo de tierras de paso.

70 Contamine, Philippe; Bompaire, Marc; Lebece, Stéphane y Sarrazin, Jean-Luc. La economía medieval. Madrid: Ed. Akal, 2000, p. 23.

71 Sánchez Corriendo, Jesús. «¿Bandidos lusitanos o pastores trashumantes?». Hispania Antiqua, 1997, vol. 21, pp. 123-154.

72 Orlandis Rovira, José. La vida en España en tiempo de los Godos. Madrid: Ed. Rialp, 1991, pp. $49-50$.

73 Pérez de Dios, Verónica y Soto García, M. a de los Reyes de. «Los Villares (Fresno Alhándiga, Salamanca): un complejo termal junto a la Vía de la Plata». Munibe. Antropologia-Arkeologia, 2017, vol. 68, pp. 237-249 (p. 247).

74 Gómez Moreno, Manuel. Documentación goda en pizarra. Madrid: Consejo Superior de Investigaciones Científicas, 1966, pp. 25-26: Pizarra n. 2 del siglo vi d. C. procedente de Santibánez de la Sierra (AEHTAM 2962) denominada como «De Eloy Bullón», pieza de 40x18x0,9 cm; también en MenÉNDEZ Pidal, Ramón. Historia de España. Vol. III, Visigodos. Madrid: Espasa Calpe, 1963, p. 415.

75 VelázQuez Soriano, Isabel. «Las pizarras visigodas. Edición crítica y estudio». Antigüedad y cristianismo. Monografías históricas sobre la Antigüedad tardia, 1989, vol. 6, pp. 31-32, 149, 613.

76 Canellas López, Ángel. Diplomática hispano-visigoda. Zaragoza: Institución Jerónimo Zurita, 1979, p. 78.

77 La normativa franca de los siglos VIII-IX también menciona el impuesto de circulación tributa et telonei in media via; igualmente expresa la idea de que los pasos fluviales han de estar libres para facilitar el tránsito naval vel ubi naves subtus pontes transire solent, sive in medio flumine ubi nullum est obstaculum; en Monumenta Germaniae Historica. Legum Sectio II. Capitularia Regnum Francorum. Tomus I (ed. A. Boretius). Hannoverae: Impensis Bibliopolii Hahniani, 1893, p. 289. 
La Lex Visigothorum atiende a las necesidades pastoriles manteniendo, sin novedades, la normativa vigente durante el mundo romano desde la Lex Agraria del siglo III a. C. ${ }^{78}$ en relación con pastos ${ }^{79}$, pasos de ganado ${ }^{80}$, protección y recuperación del mismo ${ }^{81}$. En la zona pirenaica del siglo vi el diácono Vincencius dona al monasterio de Asán varias propiedades ${ }^{82}$. Resulta interesante, porque entre los terrenos que cede se citan territorios de pastos comunales, compascuas e invernadas y veranadas como las de Saldana ${ }^{83}$.

Otras referencias que confirmarían actividades pastoriles y movimientos animales por los caminos visigodos las encontramos, por un lado, en la ya citada obra Vita Fructuosi, donde se recoge una visita al ganado de la zona que circulaba por tierras del Bier$z^{84}$. También, Valerio del Bierzo hace referencia a la matrona Teodora siendo arrollada por unos rebaños, cuando viajaba, en el siglo viıI, en busca del propio Valerio en el norte peninsular ${ }^{85}$. Deduce J. González Pantoja de este extracto que el accidente se produce al final del verano coincidiendo con el momento en que estas reses abandonan el Bierzo en busca de zonas más templadas de pastos (iuga ducti) ${ }^{86}$.

Históricamente los altos cargos militares delegaban en rangos inferiores el control de caminos, vigilancia ${ }^{87}$ y seguridad, así como el avituallamiento de tropas y ganados ${ }^{88}$.

78 En Díaz y Díaz, La vida de San Fructuoso de Braga, VSF, n. ${ }^{\circ} 2$. También la Lex Aquilia en relación a daños causados ilegalmente, y recogida en la Digesto de Justiniano (DJ. IX, 2), marca las penas en caso de "quema o deterioro» no solo de esclavos sino también de animales (DJ. III), así como la multa por asesinato de animales o esclavos, siendo la pena el pago del valor íntegro que este hubiera tenido (DJ. I).

79 LV. VIII, 3. 10.

80 LV. VIII, 3. 9. En relación con los pasos de animales, resultan interesantes las Cartas de Símaco donde pone de manifiesto el transporte regular de caballos entre Hispania y Roma. Por otro lado, Símaco nos hace llegar la preocupación que transmite a su amigo Bassus para que le cuidara en Arlés durante los meses invernales los caballos que debían llegar a los juegos por el paso de la vía que por el puerto del Palo comunicaba desde Galia hacia Caesaraugusta. Vía transitada por sus enviados a los que pedía a Bassus, les facilitara la compra de caballos. Arce Martínez, Javier. «El cursus publicus en la Hispania tardorromana». En Simposio sobre la red viaria en la Hispania romana. Zaragoza: Institución Fernando el Católico, 1990, pp. 35-40 (p. 37); Vilella Masana, Josep. "Cartas del epistolario de Q. Aurelio Símaco enviadas a Hispania». Cassiodorus, 1996, vol. 2, pp. 51-72 (p. 70). Una vez establecido el reino visigodo queda patente la relevancia de la ganadería vinculada a una economía rural y en particular a muchos monasterios, como fue el caso de la regla fructosiana, en Orlandis Rovira, Historia del reino visigodo español, pp. 265-266.

${ }^{81}$ LV. V. 1, 2; VIII, 4. 14, 17, 18, 24. Así mismo, aludimos a la ley Gungobarda en relación con los daños causados por animales (LG, XXVII, 1, 3, 4). Véase pp. 148-149.

82 In terra Boletano Sengunus porcionem meam. Segun porcionem meam. Isuste porcionem meam. Estiua Saldana porcionem meam, uel a las estiuolas ubi me porcio contingit. In terra Cesaraugustana ad Noce porcionem meam. In Trigario porcionem meam.

83 Fortacín Piedrafita, Javier. «La donación del diácono Vicente al monasterio de Asán y su posterior testamento como obispo de Huesca en el siglo vi: precisiones críticas para la fijación del texto». Cuadernos de Historia Jerónimo Zurita, 1983, vol. 47-48, pp. 7-70 (p. 60).

84 Véase nota n. ${ }^{\circ} 60$.

85 Díaz y Díaz, Valerio del Bierzo, (Replic. 6), p. 285.

86 González Pantoja, Joaquín. «Pastio agrestis. Pastoralismo en Hispania romana». En GonzÁlez Pantoja, Joaquín. (ed.). Los rebaños de Gerión: Pastores y trashumancia en Iberia antigua y medieval. Madrid: Casa de Velázquez, 2001, pp. 177-213 (p. 182).

87 Véase nota n. ${ }^{\circ} 103$.

88 Los beneficiarii y, en menor rango, los stationarii fueron soldados romanos encargados de controlar las stationes, cruces y caminos, ciudades..., sustituidos por los «hombres vigilantes de caminos» en época de 
En el caso del mundo visigodo sucede lo mismo; además de acudir a la llamada militar, el hombre reclutado podría realizar diversos servicios públicos que, en función del territorio, fuero y privilegios, podían ser de vigilar a caballo las fronteras, caminos, postas, pastos y ganado ${ }^{89}$. La vigilancia del limes será una labor de los soldados instaurada a partir de las reformas de Diocleciano y Constantino desde el siglo iv. Por tanto, para el periodo visigodo las tropas mantienen estas funciones tal y como es el caso de la vigilancia de la vía Asturica con Burdigalia, estratégicamente controlada por ser la vertebración para las Galias, así como la vía de la Plata ${ }^{90}$ y conectar con Mérida, capital diocesal ${ }^{91}$, o el mismo caso lo encontramos en la Gallaecia donde los prelados de la parroquia de Iria-Santiago ${ }^{92}$ quedan con el control de los antiguos ejes viarios romanos que dan acceso a la zona y que centurias después cobrarán más fuerza aún con el descubrimiento de los restos del Apóstol ${ }^{93}$. El control viario queda, por tanto, diseñado como tipo de dispositivo de red de fortalezas, enclavadas en el entorno de las vías a modo de sistema defensivo, especialmente en periodos bélicos, pudiendo existir de esta forma la necesidad de trazar algún camino secundario que cerrase el sistema de accesos a las zonas más rurales ${ }^{94}$.

Tiberio. Eran encargados no solo de cobrar los peajes sino también de controlar a fugitivos o preservar la seguridad de los viajeros y pastores; en VAN TILbURG, Traffic and congestion in the Roman Empire, p. 67 y SiLvela Díaz-Criado, Enrique. El proceso de profesionalización del ejército en España: el cuerpo de estado mayor, 1812-1932. Tesis doctoral inédita, 2015, p. 67.

89 LV. XI, 2, 2. Palomeque Torres, Antonio. «Contribución al estudio del ejército en los estados de la Reconquista». Anuario de Historia del Derecho Español, 1944, vol. 15, pp. 206-351 (p. 344).

90 Entre los años 469-510, los suevos consolidan el limes en el Tajo, y estabilizan el territorio delimitado por el «eje de la Plata» Astorga-Mérida. Díaz Martínez, Pablo C. "La Hispania visigoda». En Díaz Martinez, Pablo C.; Martínez Maza, Clelia y Sanz Huesma, Francisco Javier. Hispania tardoantigua y visigoda. Madrid: Istmo, 2007, pp. 259-612 (p. 304).

${ }^{9}$ Martínez Maza, Clelia y Sanz Huesma, Francisco Javier. «Hispania en el Bajo Imperio». En Díaz Martinez, Pablo C.; Martínez Maza, Clelia y Sanz Huesma, Francisco Javier. Hispania tardoantigua y visigoda. Madrid: Istmo, 2007, pp. 15-258 (pp. 86, 240). MarTin, Céline. La géographie du pouvoir dans l'Espagne visigothique. Paris: Presses Universitaires du Septentrion, 2003, p. 287, nota 42.

92 Galbán Malagón, Carlos J. «En ese país que por siglos fue el final de la tierra. Una aproximación a los orígenes del sistema castral del obispado de Iria-Santiago (ss. IX-XI)». Territorio, Sociedady Poder. Revista de Estudios Medievales, 2013, vol. 8, pp. 85-103 (p. 94, nota 30).

93 Sobre el camino francés, estudios toponímicos vinculados a la zona de Galicia confirman un paso franco por el territorio desde el siglo vi y, por ello, se propone que la toponimia "francés» se vincule al camino de Santiago por haber sido una ruta de los franci. Topónimo el de "francés» muy repetido en todo el sector norte de la cuenca superior del Ebro; en Brö̈ns, Maurice. «Los Francos en el poblamiento de la Península Ibérica durante los siglos vi y viI». Ampurias, 1956, vol. XVII-XVIII, pp. 59-77 (pp. 63-64).

${ }_{94}$ Un ejemplo de elementos defensivos altomedievales en torno a la red viaria es el caso de Caesarobriga y el cauce del río Tajo. PAcheco Jiménez, César. «Fortificaciones y vías de comunicación en época romana y altomedieval en la zona de Talavera de la Reina (Toledo)». En Caminería hispánica. Actas del IV Congreso Internacional, celebrado en Guadalajara (España), julio 1998. Madrid: Ministerio de Fomento, 2000, vol. I, pp. 53-74 (pp. 55-56). 


\section{CONTINUIDAD EN LA INFRAESTRUCTURA ROMANA}

Para completar el estudio legislativo visigodo, hemos acudido al análisis multidisciplinar tanto de las fuentes históricas como arqueológicas, las cuales avalan, así mismo, una continuidad de los pasos viarios romanos en el nuevo territorio visigodo. Estas referencias tardoantiguas sobre menciones viarias aportan información relevante para comprender la prolongación de uso y tratamiento viario según la normativa existente imperial romana aún vigente enmascarada en las nuevas leyes.

Se documentan tres pasos visigodos, ya históricos desde tiempos romanos, que conectaban los Pirineos, siendo el más cómodo la vía Domitia ${ }^{95}$. Tuvo gran tránsito el sector oriental por la provincia Narbonense. Al occidente, existían más dificultades de paso por la cadena pirenaica en la calzada procedente de Dax y Roncesvalles ${ }^{96}$. Además, parece que esta última era más insegura para los comerciantes (dados los contactos con vascones desde el siglo $\mathrm{VI}^{97}$ ), aunque siguió en uso tal y como atestigua el tesorillo de Mauleón del siglo viI.

Se conoce el paso de numerosos viajeros, peregrinos y embajadas por la ciudad de Tours. Aquí llegaba mucha información que hábilmente supo aprovechar el «obispohistoriador» Gregorio de Tours (siglo vi) autor de la célebre obra Historia de los Francos, que ofrece interesantes pinceladas históricas de Hispania ${ }^{98}$.

En el caso del martirio de Mancio ${ }^{99}$, posiblemente en torno al siglo vi, se recuerda que, no habiendo conseguido que Mancio renegara de su fe, obtuvo el martirio y su

95 Sobre los viajes de Wamba, parece que pudo ser esta ruta la que tomó desde Gerona hacia Collioure y Narbona con intención de someter la Galia; en Menéndez Pidal, Historia de España. Vol. III, Visigodos, pp. 236-237; DíAz y Díaz, Pedro Rafael. «Julián de Toledo: "Historia del Rey Wamba” (Traducción y Notas)». Florentia Iliberritana: Revista de Estudios de Antigüedad Clásica, 1990, vol. 1, pp. 89-114 (p. 97); y Julián DE Toledo. «Historia Wambae regis Gothorum Toletani expeditione». En Monumenta Germaniae Historica. Scriptorum Rerum Merovingicarum. Tomus $V$ (ed. W. Levison). Hannoverae et Lipsiae: Impensis Bibliopolii Hahniani, 1910, p. 12.

También se dirigió a Cantabria, a Toledo así como a otras ciudades hispanas, viajes de los cuales no tenemos apenas referencias sobre el tránsito viario; en JimÉnEz DE RADA, Rodrigo. Historia de los hechos de España (introducción, traducción y notas por Juan Fernández Valverde). Madrid: Alianza Editorial, 1989, pp. 122-123 y 132-133.

96 El paso por Roncesvalles queda documentado en el año 472, cuando Eurico envía sus tropas hacia la Tarraconense comandadas por el conde Gautérico, que utiliza la calzada procedente de Burdeos hacia el valle del Ebro. Parece que el asentamiento godo en el sector del Ebro a tenor de las fuentes arqueológicas se intensifica en el siglo vi; en Medrano Marqués, Manuel. «El asentamiento visigodo y musulmán de Tudején-Sanchoabarca (Fitero, Navarra)». Saldvie: Estudios de Prehistoria y Arqueología, 2004, vol. 4, pp. 261-302 (pp. 283-284).

${ }_{97}$ Se cree que el territorio vascón nunca fue dominado totalmente por la monarquía toledana; en Orlandis Rovira, La vida en España en tiempo de los Godos, p. 42.

98 Orlandis Rovira, Historia del reino visigodo español, p. 17.

99 Clavis Patrum Latinorum (CLP 2072a). 
cuerpo fue ultrajado y posteriormente "soterrado» en una calzada pública ${ }^{100}$, donde tiempo después se edificaría una basílica ${ }^{101}$.

Durante los enfrentamientos entre visigodos y bizantinos en Hispania, se corrobora la circulación y continuidad de uso de los ejes romanos (vía de la Plata ${ }^{102}$, vía Augusta ${ }^{103}$, vía 25 Augusta Emerita-Caesaraugusta ${ }^{104}$ o el paso de Mérida a Sevilla y al estrecho ${ }^{105}$ ).

100 Se trata de la calzada de Lisboa a Mérida por Évora. Itinerario de Antonino vía XII: Iter ad Olisiponem Emeritam. Allí se documenta la finca Miliana, donde vivía Mancio; en Fernández Catón, José María. San Mancio: culto, leyenda y reliquias. Ensayo de crítica hagiográfica. León: Centro de Estudios e Investigación San Isidoro, 1983, p. 182.

101 Andrés Sanz, Codoñer, Iranzo Abellán, Martín y Paniagua, La Hispania visigótica y mozárabe, p. 352.

102 Leovigildo toma la vía de la Plata para comenzar sus campañas por el norte peninsular; en GARCía Moreno, Luis A. "Zamora: del domino imperial romano al visigodo. Cuestiones de historia militar y geopolítica». En Actas del I Congreso de Historia de Zamora. Vol. 2: Prehistoria e Historia Antigua. Zamora: Instituto de Estudios Zamoranos Florián de Ocampo, 1990, pp. $445-466$ (p. 464). Arqueológicamente se registra la continuidad de uso de la calzada y del territorio más cercano, como es el caso de la calzada en Fuente de Cantos y la villa de Las Motas en Badajoz, con una evolución cronológica alto imperial hasta el siglo viII; véase SAuceda Rodríguez, Sofía. "Excavación arqueológica en el yacimiento de "Las Motas" . Extremadura Arqueológica, 2006, vol. 10, pp. 289-314, u otras villae como Cocosa, Alconétar, Jarilla de Galisteo, Casa Herrera o Dehesa de la Alberquilla entre otros ejemplos extremeños; en Fernández de la PeÑa, Francisco Javier y Matesanz Vera, Pedro. «Excavación arqueológica yacimiento número 5: Plasencia sur-Cañaveral este». Extremadura arqueológica, 2006, vol. 10, pp. 91-114 (p. 94); VArgas Calderón, José y Matesanz Vera, Pedro. "Excavación arqueológica yacimiento número 6-8: Plasencia sur-Cañaveral este». Extremadura arqueológica, 2006, vol. 10, pp. 115-144; o la ya citada villa salmantina de Los Villares; en PÉrEz DE Dios y Soto García, «Los Villares (Fresno Alhándiga, Salamanca)», pp. 237-249 (p. 247).

103 Véase nota n. ${ }^{\circ}$ 43. Desde el reinado de Eurico, y en especial con Leovigildo, se controla la mayoría de la provincia Tarraconensis y sus vías, en particular el paso de la vía Augusta; en González Barrio, Daniel. De Teudis a Leovigildo (531-586): la expansión del dominio territorial visigodo en la "Hispania" del siglo VI a partir de las fuentes escritas. Trabajo fin de Grado. Inédito. Universidad de Salamanca. 2003, pp. 96-100. Desde el punto de vista territorial parece que se establece un limes con estructuras fortificadas que se articulan en torno a la vía Augusta, con el emplazamiento privilegiado de Valencia. Así se da la confirmación de la creación de asentamientos de modelo militar y administrativo diseńados por el estado visigodo en torno al siglo VI para organización y defensa del territorio, en este caso en torno a esta calzada romana; en RIVERA I LACOMBA, Albert V. y Rosselló Mesquida, Miquel. «El final del mundo romano y el periodo visigodo (siglos IV-VIII)». En Bonet, Helena; Albiach, Rosa y Gozalbes, Manuel (coords.). Romanos y visigodos en tierras valencianas. Valencia: Museo de Prehistoria y de las Culturas de Valencia, 2003, pp. 103-111 (p. 108).

104 En el 521 el papa Hormisdas nombra a Salustio, obispo de Sevilla, vicario para la Baetica y la $L u$ sitania; ambas provincias escapan al control visigodo y, por tanto, también el paso de la calzada entre Mérida y Zaragoza pasando por Toledo, recogido en el Itinerario de Antonino XXV Alio Itinere ab Emerita Cesaragustam; en González BARrio, De Teudis a Leovigildo (531-586): la expansión del dominio territorial visigodo, p. 19 , cita 5 .

105 Clara política visigoda emplazada al Sur peninsular, en especial en la Bética; en VALverde Castro, María Rosario. Ideología, simbolismo y ejercicio del poder real en la monarquía visigoda: un proceso de cambio. Salamanca: Ediciones Universidad de Salamanca, 2000.

Bajo el reinado de Teudis y, posteriormente, de Agila la zona de dominación incluye Sevilla y Toledo, así como todo el eje desde Mérida a Sevilla en dirección al estrecho de Gibraltar; en Nelson, Carolyn A. Seymour. Regionalism in Visigothic Spain. Kansas: University Press, 1970, p. 158; GonzÁlez Barrio, De Teudis a Leovigildo (531-586): la expansión del dominio territorial visigodo, pp. 32-36. 
En la obra de Isidoro de Sevilla Historia de regibus Gothorum... se extrae alguna referencia, aunque muy vaga, pues no se detalla trayecto exacto o el estado de los caminos ${ }^{106}$, sobre la revuelta de Agila y el paso por los caminos que comunicarían ciudades como Corduba, Hispalis y Emerita. Más referencias sobre caminos romanos modernizados por visigodos aparecen en el texto de Julián de Toledo ${ }^{107}$, también en relación con el paso de tropas, aunque en este caso sí se citan el tránsito por alguna calzada romana, como la vía Hercúlea, y el acceso dirección a Huesca, Lérida y Barcelona, cuando Wamba se dirigía a sofocar la rebelión del duque Paulo, atravesando por una "vía pública» hacia la costa ${ }^{108}$. Otro acceso en esta zona del sector fronterizo a los Pirineos fue el ejemplo de uso de la ya citada vía romana que comunicaba el eje de Narbona a Barcelona, Zaragoza y Toledo ${ }^{109}$. Sin duda fue una comunicación importante, porque en el 546 Theudis legislaba desde Toledo, Atanagildo posteriormente instala allí su residencia y Wamba se recoge desde Narbona también hacia Toledo ${ }^{110}$. Gracias a la arqueología tenemos este episodio documentado por el hallazgo de piezas monetarias fechadas entre los siglos II-VIII, en especial feluses, documentados en casi todos los trazados de las principales vías romanas citadas en los viajes de Wamba y que coincidirían, así mismo, con la captura musulmana de Narbona y el paso a control franco de dicho enclave ${ }^{111}$.

Sobre Mérida no se recoge noticia del acondicionamiento de la calzada, si bien sí del puente romano, bastante deteriorado en el siglo v y rehecho en el 483 por el dux Salla y el prelado católico Zenón; en VELÁzQuez Soriano, Isabel. «El puente de Mérida: algo más que un problema de traducción». Pyrenae, 2008, vol. 39, n. ${ }^{\circ}$ 2, pp. 127-135 (p. 133). Posteriormente, este territorio quedará bajo control de Leovigildo desde el 571 (véase en Thompson, Los godos en España; Vallejo Girvés, Margarita. Bizancio y la España tardo antigua (ss. V-VIII): un capitulo de la historia mediterránea. Alcalá de Henares: Universidad de Alcalá, 1993, pp. 152-154) y a continuación de su hijo Hermenegildo (VAllejo Girvés, Bizancio y la España tardo antigua (ss. V-VIII), pp. 602-610; Orlandis Rovira, La vida en España en tiempo de los Godos, p. 145.

Sobre otras expediciones militares, si bien están documentadas, no existe referencia de los pormenores de las campańas, ni las rutas tomadas o los tiempos de desplazamiento o medios empleados; véase VALVERDE Castro, María Rosario. Los viajes de los reyes visigodos de Toledo (531-711). Madrid: Ed. La Ergástula, 2017, p. 69.

106 Isidoro de Sevilla. Historia de regibus Gothorum, Wandalorum et Suevorum (ed. Jacques-Paul Migne). Patrologia Latina. Paris: Migne, 1844-1855, vol. 83, col. 1057 (n.o 44.45.46).

107 De hinc, electis ducibus in tres turnas exercitum dividit, ita una pars ad Castrum Libae, quid est Cirritanie caput, pertenderet, secunda per Ausonensem civitatem Perinei media peteret, tertia per viam publicam iuxta ora marítima gradetur. Julián DE Toledo. «Historia Wambae regis Gothorum Toletani expeditione», n. ${ }^{\circ} 10$.

108 Gozalbes Cravioto, Enrique. «Una aproximación al estudio de las vías en la Hispania visigótica». En Criado del Val, Manuel (coord.). Camineria hispánica. Actas del II Congreso Internacional de Caminería Hispánica. Guadalajara: AACHE, 1996, vol. 1, pp. 85-94 (p. 85).

109 Véase nota n. 94.

110 Díaz Martínez, Pablo C. «El esquema provincial en el contexto administrativo de la monarquía visigoda de Toledo». En Brassous, Laurent y Panzram, Sabine (coords.). El espacio provincial en la Península Ibérica (Antigüedad tardia-Alta Edad Media). Madrid: Casa de Velázquez, 2019, pp. 77-108 (p. 82). Julián DE Toledo. "Historia Wambae regis Gothorum Toletani expeditione», n. ${ }^{\circ} 29$.

111 Ortega Ortega, Julián M. La conquista islámica de la Península Ibérica. Madrid: Ed. La Ergástula, 2018, p. 69. 
Ya ha quedado justificado el tránsito visigodo por la vía de la Plata ${ }^{112}$, y por ello hemos de aludir a la problemática inscripción en el puente de Mérida ${ }^{113}$ de época de Eurico, recogida en el Codex Toletanus ${ }^{114}$, que confirmaría que en este periodo se acondicionó la infraestructura romana poniendo de manifiesto el poder militar visigodo ${ }^{115}$.

\section{Conclusiones}

Los trabajos sobre la articulación territorial visigoda en base a su legislación no han sido tan estudiados como para cronologías romanas. Ello, en parte, es debido a que existen mayores corpora de fuentes legales romanas sobre el cursus publicus frente a los cánones visigodos. Será el estudio de la Lex Visigothorum, el Código de Justiniano o el de Teodosio, entre otros códigos legales, la base de este estudio. No obstante, el estado de la cuestión que nos atañe ha de ser analizado desde el punto de partida del trabajo de J. Arce Martínez ${ }^{116}$, quien ofrece una visión de conjunto sobre la situación del cursus publicus en la tardoantiguedad. Más en detalle, y en relación con la legislación que en este trabajo comparamos, resultan imprescindibles los enfoques de J. L. Cañizar Palacios ${ }^{117}$, donde se analiza la legislación viaria y naval, aportación que para el caso de la regulación naval, ya fue pionero el estudio de A. D'Ors ${ }^{118}$. Sobre la financiación y gastos públicos existen trabajos sobre el viario romano que completan el de J. Arce Martínez, como es el de E. Melchor Gil ${ }^{119}$, pero no específicamente para el mundo visigodo. Desde un punto de vista de estudio territorial y análisis arqueológico son clave las contribuciones para identificar el viario en centurias tardoantiguas de E. Gozalbes Cravioto ${ }^{120}$, estudio relacionado con la aportación de E. Esders ${ }^{121}$ sobre regulaciones viarias y pasos de viajeros. Estos trabajos pueden considerarse como los principales en abordar, desde diversos enfoques, la aplicación de la legislación visigoda en el tránsito y mantenimiento y, en definitiva, la regulación de la vertebración territorial para este periodo tardoantiguo que nos ocupa.

112 Véase nota n. ${ }^{\circ} 72$.

113 Sobre el texto de la inscripción véase Arce Martínez, Javier. «La inscripción del puente de Mérida de época del rey Eurico (483 d. C.)». Pyrenae, 2008, vol. 39, n. 2, pp. 121-126 (p. 121). Véase nota n. ${ }^{\circ}$ 105 .

114 Siglo viII (f. 52).

115 Vives Gatell, José. Inscripciones cristianas de la España romana y visigoda. Barcelona: Consejo Superior de Investigaciones Científicas, 1969, pp. 126-127.

116 Arce Martínez, «El Cursus publicus en la Hispania tardorromana».

117 Cañizar Palacios, José Luis. "Consideraciones sobre aspectos jurídico-legislativos en relación con las vías públicas de Hispania durante la Antigüedad Tardía». Hispania Antiqua, 2005, vol. 29, pp. 225-236; CañIzar Palacios, "Los Navicularii Hispaniarum».

118 D’Ors, «Los “transmarini negotiatores” en la legislación visigótica».

119 Melchor Gil, «Sistemas de financiación y medios de construcción de la red viaria hispana».

120 Gozalbes Cravioto, "Una aproximación al estudio de las vías en la Hispania visigótica»; GozALbes Cravioto, «La vía romana de Cástulo a Cádiz en textos medievales y del siglo Xvi».

121 EsDERs, «Reisende soll man nicht aufhalten?». 
Tanto las fuentes históricas como las arqueológicas permiten confirmar el tránsito visigodo por el antiguo viario diseńado por Roma ${ }^{122}$. Por otro lado, también se observa un encadenamiento en el pensamiento legal aplicado desde la codificación romana tardía, que, en numerosas ocasiones, es modernizada por los monarcas visigodos en sus compendios legales. Sobre la propia normativa viaria, se mantienen en gran medida las decisiones tomadas por el Imperio en especial en lo referente a límites viarios. Es patente la idea de que los caminos son de uso y disfrute público y ello conlleva unas obligaciones y prohibiciones en relación con el uso y su conservación. Además, parece cobrar protagonismo la preocupación de los monarcas visigodos por defender la seguridad de los caminos dictando severas leyes para los infractores. Igualmente, podemos concluir que fue predominante el interés por mantener una buena red comercial que se legislaba según los viajeros, sus animales y las mercancías, así como se procuró favorecer, en la medida de lo posible, los intereses ganaderos ${ }^{123}$ sobre los de los agricultores ${ }^{124}$.

Tanto la legislación visigoda hispana recogida en la Lex Visigothorum, como la lex Burgundionum para la Borgoña o el Edictum Theoderici para los italianos nororientales, conserva una fuerte influencia romana ${ }^{125}$. En el caso hispano no hay duda de las altas dosis de imitación del formato imperial. A partir de Constantino las ordenanzas se reproducen en la política altomedieval hispana, en cierta medida reflejando la imitatio imperii ${ }^{126}$. La normativa viaria, por tanto, tal y como hemos expuesto, evoluciona en la medida de las nuevas demandas sociales, pero, siempre que sea evitable, no modificará la regla romana, al igual que ocurre con la propia estructura de los caminos que son usados y escasamente reacondicionados ${ }^{127}$.

Hemos ido adelantando de manera parcial la idea de que la red viaria sería tratada como un espacio público, entendido como las estructuras financiadas desde el poder (aunque no todas), cuya función vertebradora vincula un territorio común a toda la población. En el siglo viI se alude al poder curial (aunque no exclusivamente) para organizar la financiación de la conservación de infraestructuras públicas tales como edificios, muros y puentes ${ }^{128}$. También hemos visto cómo en ocasiones se sugiere la financiación

122 Otro ejemplo del uso de la infraestructura romana queda evidenciado en vísperas de la caída del Imperio, durante el saqueo de Alarico en Roma, en el paso por la calzada Flaminia entre Piceno y Toscana dirección Roma; en Jordanes. Origen y gestas de los godos (ed. José María Sánchez Martín). Madrid: Cátedra, 2001, XXIII, p. 155.

123 Las referencias al ganado son puntuales y aisladas; no existe un compendio que regule per se la ganadería.

124 KIng, Paul D. Derecho y sociedad en el reino visigodo. Madrid: Alianza Editorial, 1972, p. 227.

125 Di Cinto, Lucia. «Fonti normative nella Lex Romana Visigothorum. Leges et iura». Studia et Documenta Historiae et Iuris, 2016, vol. 82, pp. 291-326.

126 Torrent Ruiz, Armando. "Una aproximación a la legislación visigótica hispana. La imitatio imperii». RIDROM: Revista Internacional de Derecho Romano, 2017, vol. 18, pp. 1-61 (p. 25).

${ }_{127}$ Martin, La géographie du pouvoir dans l'Espagne visigothique, p. 392. Véase también nota n. 2 para detalle de bibliografía sobre vías de comunicación romanas heredadas por el mundo visigodo hispano.

128 La transformación del tejido social visigodo provoca un cambio en la estructura poblacional. Este cambio provoca que no todas las construcciones públicas romanas se conserven, en especial las urbanas. Por ejemplo, la mayoría de los bańos desaparece, el circo de Mérida queda desierto y el foro de Tarragona se reutiliza como espacio residencial; en Curchin, Leonard A. "Curials and local government in Visigothic 
por la comunidad, como deber adquirido al disfrutar de un espacio común y público de la colectividad, teniendo derecho de uso (paso) y prohibición del deterioro u obstaculización del tránsito ajeno. Por tanto, el pensamiento conservado en todo el cuerpo legal tardoantiguo $^{129}$ sobre este espacio público, que son los caminos, vendría heredado igualmente del mundo clásico, tal y como se refleja en la Digesto que proclama «libertad de uso general en las vías y caminos públicos» (Dig. 43,7,1) ${ }^{130}$ en el también citado Edicto de Pomponio y Ulpiano ${ }^{131}$.

\section{Fuentes Históricas}

Braulio Caesaraugustanus, Isidorus Hispalensis. Epistulae, Confessio uel professio Iudaeorum ciuitatis Toletanae (eds. Ruth Miguel Franco y José Carlos Martín-Iglesias). Turnhout: Brepols, 2018.

Clavis Patrum Latinorum (ed. Eligius Dekkers). 3. a ed. Turnhout: Brepols, 1995.

Codex Theodosianus (ed. Theodor Mommsen y Paul M. Meyer). 2 vols. Berlin: Weidmann, 1905.

Código de Eurico (edición, palingenesia, índices por Álvaro d’Ors). 2. a ed. Madrid: Boletín Oficial del Estado, 2014.

Cuerpo del derecho civil romano. T. III. Digesto (traducción y compilación de Ildefonso L. García del Corral). Barcelona: [Jaime Molinas, editor], 1897.

Drew, Katherine Fischer. The Burgundian Code. Book of Constitutions or Law of Gundobad. Philadelphia: University of Pennsylvania Press, 1972.

GaYo. Institvtionvm. Leipzig: Ed. E. Seckel, B. Keubler, 1935.

Gregorio de Tours. Historia Francorum (traducción E. Brehaut), 1916.

Hyginvs et Sicvlvs Flaccvs. Opvscula Agrimensorvm Vetervm (traducción y comentarios de M. ${ }^{a}$ J. Castillo Pascual). Logroño: Universidad de La Rioja, 2011.

Isidoro de Sevilla. Etimologías (ed. José Oroz Reta y Manuel A. Marcos Casquero). Madrid: Editorial Católica, 1982.

Isidoro de Sevilla. Historia de regibus Gothorum, Wandalorum et Suevorum (ed. Jacques-Paul Migne). Patrologia Latina. Paris: Migne, 1844-1855, vol. 83, col. 1057.

Jiménez DE RADA, Rodrigo. Historia de los hechos de España (introducción, traducción y notas por Juan Fernández Valverde). Madrid: Alianza Editorial, 1989.

Jordanes. Origen y gestas de los godos (ed. José María Sánchez Martín). Madrid: Cátedra, 2001.

Julián de Toledo. "Historia Wambae regis Gothorum Toletani expeditione». En Monumenta Germaniae Historica. Scriptorum Rerum Merovingicarum. Tomus V(ed. W. Levison). Hannoverae et Lipsiae: Impensis Bibliopolii Hahniani, 1910.

Hispania». Antiquité Tardive, 2018, vol. 26, pp. 225-240 (pp. 232-233) y Diarte Blasco, Pilar. La configuración urbana de la Hispania tardoantigua. Transformaciones y pervivencias de los espacios públicos romanos (s. III-VI d. C). Oxford: Archaeopress, 2012.

129 Tanto la Lex Visigothorum como el Código Burgundio, el Código de Eurico o la Ley Langobarda aluden al término «camino público» y manifiestan la preocupación por un correcto uso de un espacio comunal, regulando, tal y como ya hemos presentado en estas páginas, diversas sanciones para los casos de menoscabo en la red viaria ya sea por desgaste, descuido o imprudencia.

130 Véase p. 145.

131 Véase notas n. ${ }^{\circ 5} 5,10$ y 35. 
«Leges Langobardorum». Monumenta Germaniae Historica. Legum Tomus IIII. Hannoverae: Impensis Bibliopolii Aulici Hahniani, 1868.

Legis Romanae Wisigothorum. Fragmenta ex codice palimpsesto Sanctae Legionensis Ecclesiae. Matriti: apud Ricardum Fe, Regiae Academiae Typographum, 1896.

«Lex Romana Burgundionum» (ed. R. L. von Salis). En Monumenta Germaniae Historica. Legum Sectio I. Tomi II. Pars I. Hannoverae: Impensis Bibliopolii Hahniani, 1892.

Liber Iudiciorum (estudio preliminar de Rafael Ramis Barceló; traducción y notas de Pedro Ramis Serra y Rafael Ramis Barceló). Madrid: Agencia Estatal Boletín Oficial del Estado, 2015.

Monumenta Germaniae Historica. Legum Sectio II. Capitularia Regnum Francorum. Tomus I (ed. A. Boretius). Hannoverae: Impensis Bibliopolii Hahniani, 1893.

\section{REFERENCIAS BIBLIOGRÁFICAS}

Álvarez Maurín, María Pilar. Diplomática asturleonesa. Terminología toponímica. León: Universidad de León, 1994.

Andrés Sanz, M. a Adelaida; Codoñer, Carmen; Iranzo Abellán, Salvador; Martín, José Carlos y Paniagua, David. La Hispania visigótica y mozárabe: dos épocas en su literatura. Salamanca: Universidad de Extremadura-Ediciones Universidad de Salamanca, 2010.

Arce Martínez, Javier. «El cursus publicus en la Hispania tardorromana». En Simposio sobre la red viaria en la Hispania romana. Zaragoza: Institución Fernando el Católico, 1990, pp. 35-40.

Arce Martínez, Javier. "La inscripción del puente de Mérida de época del rey Eurico (483 d. C.)». Pyrenae, 2008, vol. 39, n. ${ }^{\circ}$ 2, pp. 121-126.

Brö̈ns, Maurice. «Los Francos en el poblamiento de la Península Ibérica durante los siglos vi y vII». Ampurias, 1956, vol. XVII-XVIII, pp. 59-77.

Canellas López, Ángel. Diplomática hispano-visigoda. Zaragoza: Institución Jerónimo Zurita, 1979.

Cañizar Palacios, José Luis. «Consideraciones sobre aspectos jurídico-legislativos en relación con las vías públicas de Hispania durante la Antigüedad Tardía». Hispania Antiqua, 2005, vol. 29, pp. 225-236.

Cañizar Palacios, José Luis. «Los Navicularii Hispaniarum en el contexto de la documentación legislativa tardo antigua». Hispania Antiqva, 2009-2010, vol. XXXIII-XXXIV, pp. 295-310.

CARr, Karen Eva. Vandals to Visigoths: Rural Settlement Patterns in Early Medieval Spain. Ann Arbor: University of Michigan Press, 2002.

Collins, Roger. Early medieval Spain. Unity in Diversity, 400-1000. London: Palgrave Macmillan, 1995.

Contamine, Philippe; Bompaire, Marc; Lebece, Stéphane y Sarrazin, Jean-Luc. La economía medieval. Madrid: Ed. Akal, 2000.

Curchin, Leonard A. "Curials and local government in Visigothic Hispania». Antiquité Tardive, 2018, vol. 26, pp. 225-240.

D'Ors, Álvaro. "Los “transmarini negotiatores" en la legislación visigótica». En Estudios de Derecho Internacional. Homenaje al profesor Camilo Barcia Trelles. Santiago de Compostela: Universidad de Santiago de Compostela, 1958, pp. 467-483.

Di Cinto, Lucia. "Fonti normative nella Lex Romana Visigothorum. Leges et iura». Studia et Documenta Historiae et Iuris, 2016, vol. 82, pp. 291-326.

Diarte Blasco, Pilar. La configuración urbana de la Hispania tardoantigua. Transformaciones y pervivencias de los espacios públicos romanos (s. III-VI d. C). Oxford: Archaeopress, 2012. 
Díaz Martínez, Pablo C. «La Hispania visigoda». En Díaz Martinez, Pablo C.; Martínez Maza, Clelia y Sanz Huesma, Francisco Javier. Hispania tardoantigua y visigoda. Madrid: Istmo, 2007, pp. 259-612.

Díaz Martínez, Pablo C. «El esquema provincial en el contexto administrativo de la monarquía visigoda de Toledo». En Brassous, Laurent y Panzram, Sabine (coords.). El espacio provincial en la Peninsula Ibérica (Antigüedad tardia-Alta Edad Media). Madrid: Casa de Velázquez, 2019, pp. 77-108.

Díaz y Díaz, Manuel Cecilio. La vida de San Fructuoso de Braga. Estudio y edición crítica. Braga: Diário do Minho, 1974.

Díaz y Díaz, Manuel Cecilio. Valerio del Bierzo. Su persona. Su obra. León: Centro de Estudios e Investigación San Isidoro, 2006.

Díaz y DíAz, Pedro Rafael. «Julián de Toledo: "Historia del Rey Wamba” (Traducción y Notas)». Florentia Iliberritana: Revista de Estudios de Antigüedad Clásica, 1990, vol. 1, pp. 89-114.

EsDers, Stefan. «Reisende soll man nicht aufhalten? Über Infrastrukturen sowie erwünschte und unerwünschte Mobilität im westgotischen Spanien». En Czegunn, Ignacio et ál. (coords.). Wasser-Wege-Wissen auf der iberischen Halbinsel vom Römischen Imperium bis zur muselmanischen Herrschaft I. Tagungsband zur gleichnamigen Tagung in Elche 2014. Baden-Baden: Nomos Verlag, 2016, pp. 151-182.

Fernández Catón, José María. San Mancio: culto, leyenda y reliquias. Ensayo de crítica hagiográfica. León: Centro de Estudios e Investigación San Isidoro, 1983.

Fernández de la Peña, Francisco Javier y Matesanz Vera, Pedro. «Excavación arqueológica yacimiento número 5: Plasencia sur-Cañaveral este». Extremadura arqueológica, 2006, vol. 10, pp. 91-114.

Fortacín Piedrafita, Javier. «La donación del diácono Vicente al monasterio de Asán y su posterior testamento como obispo de Huesca en el siglo vi: precisiones críticas para la fijación del texto». Cuadernos de Historia Jerónimo Zurita, 1983, vol. 47-48, pp. 7-70.

Frighetto, Renan. Valério do Bierzo. Autobiografía. Noia (A Coruña): Ed. Toxosoutos, 2005.

Galbán Malagón, Carlos J. «En ese país que por siglos fue el final de la tierra. Una aproximación a los orígenes del sistema castral del obispado de Iria-Santiago (ss. IX-XI)». Territorio, Sociedad y Poder. Revista de Estudios Medievales, 2013, vol. 8, pp. 85-103.

García Garrido, Manuel. «Derecho a la caza y "Ius Prohibendi" en Roma». Anuario de Historia del Derecho Español, 1959, vol. 26, pp. 269-336.

García Moreno, Luis A. «Zamora: del domino imperial romano al visigodo. Cuestiones de historia militar y geopolítica». En Actas del I Congreso de Historia de Zamora. Vol. 2: Prehistoria e Historia Antigua. Zamora: Instituto de Estudios Zamoranos Florián de Ocampo, 1990, pp. 445-466.

Gómez Moreno, Manuel. Documentación goda en pizarra. Madrid: Consejo Superior de Investigaciones Científicas, 1966.

González Barrio, Daniel. De Teudis a Leovigildo (531-586): la expansión del dominio territorial visigodo en la "Hispania" del siglo VI a partir de las fuentes escritas. Trabajo fin de Grado. Inédito. Universidad de Salamanca. 2003.

González Pantoja, Joaquín. «Pastio agrestis. Pastoralismo en Hispania romana». En González Pantoja, Joaquín. (ed.). Los rebaños de Gerión: Pastores y trashumancia en Iberia antigua y medieval. Madrid: Casa de Velázquez, 2001, pp. 177-213.

Gozalbes Cravioto, Enrique. "Una aproximación al estudio de las vías en la Hispania visigótica». En Criado del Val, Manuel (coord.). Caminería hispánica. Actas del II Congreso Internacional de Caminería Hispánica. Guadalajara: AACHE, 1996, vol. 1, pp. 85-94. 
Gozalbes Cravioto, Enrique. «La vía romana de Cástulo a Cádiz en textos medievales y del siglo xvI». En Caminería hispánica. Actas del IV Congreso Internacional, celebrado en Guadalajara (España), julio 1998. Madrid: Ministerio de Fomento, 2000, vol. I, pp. 73-90.

KInG, Paul D. Derecho y sociedad en el reino visigodo. Madrid: Alianza Editorial, 1972.

Malavé Osuna, Belén. Régimen jurídico financiero de las obras públicas en el derecho romano: los modelos privado y público de financiación. Madrid: Dykinson, 2007.

Martin, Céline. La géographie du pouvoir dans l'Espagne visigothique. Paris: Presses Universitaires du Septentrion, 2003.

Martín Castro, Antonio. "Ad Aras y La Carlota. Estado actual de una hipótesis a la luz de nueva información». Antiqvitas, 2010, vol. 22, pp. 107-119.

Martínez Maza, Clelia y Sanz Huesma, Francisco Javier. «Hispania en el Bajo Imperio». En Díaz Martinez, Pablo C.; Martínez Maza, Clelia y Sanz Huesma, Francisco Javier. Hispania tardoantigua y visigoda. Madrid: Istmo, 2007, pp. 15-258.

Medrano Marqués, Manuel. «El asentamiento visigodo y musulmán de Tudején-Sanchoabarca (Fitero, Navarra)». Saldvie: Estudios de Prehistoria y Arqueología, 2004, vol. 4, pp. 261-302.

Melchor Gil, Enrique. «Sistemas de financiación y medios de construcción de la red viaria hispana». Habis, 1992, vol. 23, pp. 121-137.

Menéndez Pidal, Ramón. Historia de España. Vol. III, Visigodos. Madrid: Espasa Calpe, 1963.

Nelson, Carolyn A. Seymour. Regionalism in Visigothic Spain. Kansas: University Press, 1970.

Orlandis Rovira, José. Historia del reino visigodo español: los acontecimientos, las instituciones, la sociedad, los protagonistas. Madrid: Ed. Rialp, 1988.

Orlandis Rovira, José. La vida en España en tiempo de los Godos. Madrid: Ed. Rialp, 1991.

Ortega Ortega, Julián M. La conquista islámica de la Península Ibérica. Madrid: Ed. La Ergástula, 2018.

Ortuño PÉRez, M. a Eugenia. «Algunas consideraciones sobre las servidumbres en la Lex Romana Burgundionum». Anuario da Facultade de Dereito da Universidade da Coruña, 2008, vol. 12, pp. 707-721.

Pacheco Jiménez, César. "Fortificaciones y vías de comunicación en época romana y altomedieval en la zona de Talavera de la Reina (Toledo)». En Caminería hispánica. Actas del IV Congreso Internacional, celebrado en Guadalajara (España), julio 1998. Madrid: Ministerio de Fomento, 2000, vol. I, pp. 53-74.

Palomeque Torres, Antonio. "Contribución al estudio del ejército en los estados de la Reconquista». Anuario de Historia del Derecho Español, 1944, vol. 15, pp. 206-351.

Pérez de Dios, Verónica y Soto García, M. ${ }^{a}$ de los Reyes de. «Los Villares (Fresno Alhándiga, Salamanca): un complejo termal junto a la Vía de la Plata». Munibe. Antropologia-Arkeologia, 2017, vol. 68, pp. 237-249.

Rivera i Lacomba, Albert V. y Rosselló Mesquida, Miquel. «El final del mundo romano y el periodo visigodo (siglos IV-ViII)». En Bonet, Helena; Albiach, Rosa y Gozalbes, Manuel (coords.). Romanos y visigodos en tierras valencianas. Valencia: Museo de Prehistoria y de las Culturas de Valencia, 2003, pp. 103-111.

SÁnchez Corriendo, Jesús. «¿Bandidos lusitanos o pastores trashumantes?». Hispania Antiqua, 1997, vol. 21, pp. 123-154.

Sauceda Rodríguez, Sofía. "Excavación arqueológica en el yacimiento de "Las Motas"». Extremadura Arqueológica, 2006, vol. 10, pp. 289-314.

Silvela Díaz-Criado, Enrique. El proceso de profesionalización del ejército en España: el cuerpo de estado mayor, 1812-1932. Tesis doctoral inédita, 2015.

Thompson, Edward Arthur. Los godos en España. Madrid: Alianza Editorial, 1969. 
Torrent Ruiz, Armando. «Una aproximación a la legislación visigótica hispana. La imitatio imperii». RIDROM: Revista Internacional de Derecho Romano, 2017, vol. 18, pp. 1-61.

VAllejo Girvés, Margarita. Bizancio y la España tardo antigua (ss. V-VIII): un capitulo de la historia mediterránea. Alcalá de Henares: Universidad de Alcalá, 1993.

Valverde Castro, María Rosario. Ideología, simbolismo y ejercicio del poder real en la monarquía visigoda: un proceso de cambio. Salamanca: Ediciones Universidad de Salamanca, 2000.

Valverde Castro, María Rosario. Los viajes de los reyes visigodos de Toledo (531-711). Madrid: Ed. La Ergástula, 2017.

VAn Tilburg, Cornelis. Traffic and congestion in the Roman Empire. London: Routledge, 2007.

Vargas Calderón, José y Matesanz Vera, Pedro. «Excavación arqueológica yacimiento número 6-8: Plasencia sur-Cañaveral este». Extremadura arqueológica, 2006, vol. 10, pp. 115-144.

Velázquez Soriano, Isabel. «Las pizarras visigodas. Edición crítica y estudio». Antigüedad y cristianismo. Monografías históricas sobre la Antigüedad tardía, 1989, vol. 6.

Velázquez Soriano, Isabel. «El puente de Mérida: algo más que un problema de traducción». Pyrenae, 2008, vol. 39, n. ${ }^{\circ}$ 2, pp. 127-135.

Vilella Masana, Josep. "Cartas del epistolario de Q. Aurelio Símaco enviadas a Hispania». Cassiodorus, 1996, vol. 2, pp. 51-72.

Vives Gatell, José. Concilios visigóticos e hispano-romanos. Vol. 1. Barcelona-Madrid: Consejo Superior de Investigaciones Científicas, 1963.

Vives Gatell, José. Inscripciones cristianas de la España romana y visigoda. Barcelona: Consejo Superior de Investigaciones Científicas, 1969. 